\title{
Disambiguation by community membership
}

\author{
RICHARD J. GERRIG and MICHAEL L. LITTMAN \\ Yale University, New Haven, Connecticut
}

\begin{abstract}
To interpret utterances in conversations, listeners must often make reference to the common ground they share with speakers. For example, when faced with an utterance such as "That game was a disaster," listeners must decide whether they share common assumptions about what outcome would be disastrous. In our experiments, we examine how common ground, as encoded in community membership, is used to constrain judgments about the interpretations of ambiguous utterances. In Experiment 1, subjects were sensitive to community membership when they were asked to evaluate the interpretations at a leisurely pace. Experiment 2 replicated this result with greater time pressure. Experiment 3 demonstrated that judgments based on assessments of community membership were equivalent to those based on certain knowledge, except when the judgments were challenged. The results suggest that models of memory retrieval during language comprehension should make mention of access to common ground.
\end{abstract}

To determine what speakers mean, conversational participants must often draw on knowledge absent from the linguistic environment. Suppose, for example, a speaker says, "I'll never eat at the Stewpot again. The waiters there are terribly rude." The addressee would have to access generic knowledge about restaurants to understand why the behavior of waiters would be relevant to choices about dining out (see Schank \& Abelson, 1977). A major goal of psycholinguistic research has been to specify how it is that such generic knowledge is accessed and used in the course of comprehension (e.g., Abbott, Black, \& Smith, 1985; Bower, Black, \& Turner, 1979; Graesser, Gordon, \& Sawyer, 1979; Sharkey \& Mitchell, 1985; Sharkey \& Sharkey, 1987; Walker \& Yekovich, 1984). This body of research presupposes that the knowledge structures are shared by the vast majority of members of a particular culture.

The determination of meaning, however, also often relies on knowledge shared by smaller groups of individuals-as small as the common ground of particular conversational dyads (Clark \& Carlson, 1981; Clark \& Marshall, 1981). For example, one night on a talk show, comedian Billy Crystal commented that a city he had recently visited was "not an E-ticket." Some members of the audience laughed heartily; others responded with puzzled silence. The audience members who could understand and appreciate Crystal's remark belonged to

\footnotetext{
Preparation of this article was supported in part by Grant 1 R03 MH43764-01Al from the National Institute of Mental Health. We are indebted to Andrew Swartz for his keen insights and unflagging contributions in early phases of this research. We are grateful to Arthur Samuel for his detailed comments on an earlier draft of this article. We thank Neil Bermel for assistance in writing scenarios and Amelia Eisch and Hank Hsu for assistance in data collection. Michael Littman is now a member of technical staff at Bellcore. Requests for reprints may be addressed to Richard J. Gerrig, Department of Psychology, Yale University, P.O. Box 11A Yale Station, New Haven, CT 06520-7447.
}

the community of individuals who had visited Disneyland while it still had a system that graded the attractions from A-tickets (the worst) to E-tickets (the best). Our goal in this project is to examine how such knowledge shared in communities wields its influence on language processing.

Previous research has largely examined how the accumulation and evaluation of common ground is manifested in language production (e.g., Clark \& WilkesGibbs, 1986; Isaacs \& Clark, 1987; Schober \& Clark, 1989). For example, speakers were more likely to refer to pictures of New York City landmarks with proper names (e.g., the Citicorp Building) than with definite descriptions (e.g., the tall building with the triangular top) when they believed they were conversing with a New Yorker (Isaacs \& Clark, 1987). Descriptions produced with respect to strong common ground also tend to be figurative and diverse in their lexical content (Krauss, 1987). Evidence for the effects of common ground on comprehension have been more indirect. Typically, information provided in the linguistic environment has comprised the common ground used to constrain interpretations of ambiguous utterances. For example, an utterance, such as "Sure is nice and warm in here," when embedded in appropriate contexts, can become either a sarcastic indirect request, meaning "Please close the window," or a straightforward comment, meaning "This room is warm." With appropriate information provided explicitly in the linguistic environment, readers are easily able to recover either of these meanings-the processing advantage, in fact, accrues to the seemingly more complex sarcastic indirect requests (Gibbs, 1986). In general, recovery of complex speakers' meanings based on linguistically explicit common ground is as easy as or easier than the recovery of seemingly simple literal meanings (see Gibbs, 1984,1987 , for reviews). In our research, we wish to extend this result by exploring how the knowledge encoded in common ground functions when it is not explicit in the linguistic environment. 
Our technique for approaching this question was to create situations in which the interpretation of an ambiguous utterance depended on membership in a particular community-in this case, the community of Yale undergraduates. Consider this brief story:

You are walking back to your car after a football game between Yale and Brown. While you are waiting to cross a street, a good friend walks up to you and says, "That game was a disaster."

The utterance "That game was a disaster" is ambiguous: Depending on who "you" are and who your "good friend" is, it could imply that either or both teams had played poorly. As determined through pretesting, Yale undergraduates interpreted the utterance to mean Yale had lost the game. If we were to ask Brown undergraduates, we imagine they would believe that the utterance implied that Brown had lost the game.

Note that there are at least two methods by which listeners could verify an interpretation of the utterance “That game was a disaster" (Gerrig, 1986). The first is the one we have already described: Listeners can access common-grounded knowledge from memory along the same lines that inferences are drawn on the basis of generic knowledge. We can call this efficient use of common ground direct processing. The second method, which can be called indirect processing, is more akin to problem solving. If the listeners do not share appropriate common ground, they may nonetheless be able to puzzle out what the speaker might have meant on the basis of more generic knowledge. Even in circumstances in which speakers are specifically enjoined to conceal their meanings from third parties, the "overhearers" are often able to root the meanings out (Clark \& Schaefer, 1987). For example, even audience members who could not fully enjoy Billy Crystal's joke certainly understood that he was saying something negative. Because listeners would have to reason more deliberately in carrying out disambiguation through this indirect, problem-solving-like process, we predict that they would verify interpretations with less confidence.

We can test this contrast between direct and indirect processing by minimally rewriting our scenario to undermine the presumption of community membership. Consider this alternative scenario:

You are walking back to your car after a football game between Yale and Brown. While you are waiting to cross a street, a stranger walks up to you and says, "That game was a disaster."

The difference here is subtle but important: It is a stranger, rather than a good friend, who utters, "That game was a disaster." Under these circumstances, readers should find it more difficult to confirm interpretations of the utterance, because they cannot be certain that they share common assumptions about what state of the world would be disastrous. Our first step in exploring the efficient deployment of common ground was to demonstrate that readers' confidence in their interpretations varies as a function of assessed community membership.

\section{EXPERIMENT 1}

\section{Norming Study}

To begin, we needed a large number of scenarios in which the dominant interpretations of ambiguous utterances were determined by membership in the Yale undergraduate community. We wrote 40 scenarios, each of which ended with an ambiguous utterance made by a speaker with whom the reader was intended to share common ground (e.g., a good friend, a boy/girlfriend, a roommate). After each scenario, two possible interpretations appeared (the order of the alternatives was counterbalanced across subjects). Consider this example (Yale undergraduates favored Interpretation A):

You have a 10-page paper due the next day for a small seminar. You call the professor, with whom you have had several private meetings, to ask her if you can hand it in the following Monday. She replies, "What do you think your classmates would say?"

A. You should hand in your paper on time.

B. You can hand your paper in on Monday.

Eighteen Yale undergraduates read the scenarios and indicated which interpretation they believed was correct by circling a number on a rating scale of 1 (I thought it meant $A$ ) to 9 (I thought it meant $B$ ). From the 40 scenarios, we selected for use in the experimental phase of the study the 20 for which there was most clearly a dominant interpretation.

\section{Friends and Strangers}

In Experiment 1, we sought to demonstrate that, at least when given time to reason about the situation, readers could be sensitive to quality of common ground, as encoded by community membership. The readers saw each of the 20 scenarios selected in the norming study either in its original strong common-ground version or in an altered impoverished common-ground version. We created impoverished common ground by replacing "friend" with "stranger" or by otherwise suggesting in a mild fashion that the speaker no longer (overtly) shared community membership with the reader (see Appendix A for sample stories). The subject read the scenarios and indicated the strength of his/her preference for one or the other interpretation.

\section{Method}

Subjects. Forty Yale undergraduates participated in Experiment 1 . All were enrolled in introductory psychology and received class credit. The subjects were native speakers of English.

Materials and Design. The two versions of each of the 20 scenarios were assigned to two lists such that each list contained 10 scenarios with strong common ground and 10 with impoverished common ground. Each scenario ended with an ambiguous utterance that afforded two possible interpretations. The utterances were 
either assertions or questions and were intended to have their conventional force. The two interpretations were presented after each scenario in a counterbalanced order. Overall, thus, there were four different forms of each item (two strengths of common ground with two orders of interpretations), assigned to four booklets. Four scenarios appeared on each page of each booklet. Each subject received a booklet with the five pages shuffled in a different order.

Procedure. The subjects were instructed to read each scenario and then to indicate the strength with which they agreed with one of the two proffered interpretations. The rating scale was identical to that used in the norming study: 1 indicated 1 thought it meant $A, 9$ indicated $I$ thought it meant $B$.

\section{Results and Discussion}

The data were transformed so that higher ratings always meant more agreement with the interpretation that had been deemed dominant in the norming study. The readers gave a higher mean rating (7.03) to these interpretations when they shared strong common ground than when common ground was impoverished (6.12) $\left[\min F^{\prime}(1,27)=\right.$ $9.19, p<.01]$. Thus, when they were able to take the time to carefully consider the identity of the speaker, the readers were more certain of their interpretations; they were more confident that they understood their friends and, hence, less confident that they understood strangers. Two aspects of these ratings are worthy of further note. First, even with strong common ground, there was still ambiguity: The mean rating was reliably below the "certain" value of $9\left[\min F^{\prime}(1,27)=71.93, p<.001\right]$. The interpretations were dominant, but not certain, with respect to common ground. Second, even with impoverished common ground, the readers preferred the dominant interpretation: The mean rating was reliably above the neutral rating of $5\left[\min F^{\prime}(1,26)=10.61, p<.005\right]$. The readers still preferred the interpretation that is dominant in their community.

The results of Experiment 1 demonstrate that readers can be sensitive to the knowledge encoded by community membership in the way that they evaluate interpretations of ambiguous utterances. However, what is true when readers have ample time to reason need not be true under the time pressures of conversation. This dissociation has been demonstrated, for example, with respect to metaphor comprehension (Gerrig, 1989; Gerrig \& Healy, 1983). Readers given the opportunity to consider metaphorical utterances at a leisurely pace are easily able to make distinctions about differential quality. These differences in aptness, however, have little effect on the time course of comprehension under conversational constraints. In Experiment 2, we sought to rule out such a dissociation in sensitivity to community membership. We approximated some of the time pressures of real conversation by requiring the readers to respond as quickly as possible to interpretations of the ambiguous utterances. Our goal was to demonstrate that the knowledge encoded in community membership is accessed efficiently even under more rigorous processing demands.

\section{EXPERIMENT 2}

In Experiment 2, we required the students to read short scenarios on a computer screen. Each scenario ended with an ambiguous utterance made by a speaker with whom the reader could be assumed to share either strong or impoverished common ground. Following the scenario, either the dominant or the nondominant interpretation of the ambiguity (as confirmed in Experiment 1) appeared on the screen. The readers were required to indicate as swiftly as possible whether the proferred interpretation was appropriate given their understanding of the scenario.

This experimental situation was intended to capture some of the features of real conversation: Under normal conditions, addressees must quickly commit themselves to an interpretation of each utterance so that, for example, they can formulate their responses. Thus, our primary measure was decision time, the latency with which the subjects agreed or disagreed with an interpretation. (Because this measure requires the somewhat unorthodox pooling of "yes" and "no" responses, we will also report the unpooled latencies.) We predict that strong common ground will allow the subjects to confirm (or disconfirm) the interpretations swiftly. Impoverished common ground will require them to engage in more indirect reasoning, producing longer judgment latencies.

\section{Method}

Subjects. Twenty-eight Yale undergraduates participated in Experiment 2 for course credit. They were all native speakers of English.

Apparatus. Experiment 2 was conducted on two personal computers, an IBM PC and an IBM PC XT, which measured reading and decision times. The participants sat in front of an IBM monochrome display, with their hands resting on the keyboard. They used buttons on the keyboard to make appropriate responses. The sentences were displayed in the center of the screen in standard upper- and lowercase type.

Materials. The scenarios were identical to those used in Experiment 1 (for samples, see Appendix A). Each of the 20 scenarios appeared in strong and impoverished common-ground versions. Each one concluded with an ambiguous utterance, which was followed by either the dominant or the nondominant interpretation of the ambiguity. When a sentence from one of the scenarios exceeded the length of the computer screen, it was subdivided in a natural fashion so that the subjects read it in two successive segments. However, the ambiguous sentence at the end of each scenario was always isolated (i.e., "He said" or "She replied" appeared separately) and was presented as a single line.

We also wrote 20 filler scenarios. These scenarios were similar in content to the experimental stories (see Appendix B for samples). They also ended with ambiguous utterances. However, the interpretations proffered for the ambiguities were clearly not possible. Our intention was to provide a baseline against which the readers' performance would be calibrated for the experimental scenarios. There were also five practice scenarios that were representative of both the filler and the experimental items.

Design and Procedure. We constructed four lists of scenarios such that each scenario appeared in a different form (two types of common ground with two possible interpretations) on each list. Each subject read one list of scenarios in a different random order. 
The experimental session began with five practice stories. These stories served to familiarize the subjects with the procedure and with the mapping of functions to buttons on the keyboard.

Each scenario in both the practice and the real phase of the experiment began when the words "Press NEXT for next story" appeared on the screen. A label on the keyboard indicated that the A key was the NEXT button. The subject pressed NEXT to initiate each scenario and to indicate that each sentence, or part of a sentence, had been fully understood. Once NEXT was pressed, a new sentence appeared immediately. This procedure continued throughout the scenario. After five, six, or seven lines, the ambiguous utterance appeared. Once the subject pressed NEXT to indicate that he/she had read the utterance, a beep from the terminal signaled that the following sentence would be an interpretation of the ambiguity. The subject was instructed to respond "yes" or "no", ("that's what I think the speaker would mean by using the utterance in this context') by pressing either the $J$ or the $K$ buttons on the keyboard. These keys were appropriately labeled and were counterbalanced across subjects. Once the yes/no judgment had been made, "Press NEXT for next story" reappeared on the terminal. This procedure was followed for the five practice and 20 experimental scenarios.

\section{Results and Discussion}

Table 1 presents four main measures of performance from Experiment 2. The decision times represent mean latencies for the readers' yes/no judgments (and then "yes" and "no" decision times are reported separately). The reading times represent the mean amount of time the readers took to understand the ambiguous utterances. Error rates for Experiment 2 consist of the scenarios on which the subjects' decision or reading times fell beyond a clear gap (approximately $1 \mathrm{sec}$ ) in the distributions of responses. Although there were no formal errors possible in Experiment 2 (because the subjects were indicating agreement with their personal interpretation), the extreme values give some indication of the relative difficulty of judgments for the different versions of the scenarios. Mean decision and reading times exclude the extreme values (if either value was out of bounds, both latencies were excluded from further analyses). Table 1 also presents the percent "yes" responses to the dominant interpretation.

The subjects were able to take community membership into account when they were called upon to confirm interpretations of ambiguities. Decision times for scenarios with strong common ground were reliably lower than were those from scenarios with impoverished common ground $\left[\min F^{\prime}(1,44)=4.89, p<.05\right]$. There was limited evidence for an effect of dominance, with responses to the nondominant interpretation being longer [item analysis, $F(1,16)=3.79, M S_{\mathrm{e}}=0.72, p=.07$; subject analysis, $\left.F(1,24)=1.79, M S_{\mathrm{e}}=2.01, p>.10\right]$. There was, however, no indication of an interaction (both $F \mathrm{~s}<1.0$ ). The results of Experiment 1 demonstrated readers' sensitivity to common ground when they were in situations of relative leisure. The results of Experiment 2 demonstrated that this continues to be true when readers were asked to perform under constraints more typical of real conversation.

Because our methodology allows greatly varying numbers of observations to contribute to each of the separate mean "yes" and "no" latencies, our comments about them are not undergirded by inferential statistics. Nonetheless, when we compare the decision times for the more probable responses, we find a 515-msec increase from strong to impoverished common ground for "yes" responses to the dominant interpretations and a $947-\mathrm{msec}$ increase for "no" responses to the nondominant interpretations. Also noteworthy in these separate analyses is an exception to the pattern that "no" responses took longer than "yes" responses: This relationship was reversed for the rare occasions on which the readers said "yes" to nondominant interpretations under circumstances of strong common ground. The readers took longer to say "yes" than to say "no" to an interpretation when common ground argued strongly against the interpretation.

The reading times showed little effect of strength of common ground [item analysis, $F(1,16)=2.59, M S_{\mathrm{e}}=$ $0.26, p>.10$; subject analysis, $F(1,24)<1.0, M S_{\mathrm{e}}=$ $0.92]$. These results suggest, perhaps, that the subjects were deferring some of the processing of the utterance until they considered the specific interpretations. With this methodology, decision times provide the more critical evidence for the subjects' exploitation of common ground. There was evidence, however, for an effect of the dominance of the interpretation (which was surprising, because this manipulation did not become relevant until after the subjects had understood the ambiguity) [item analysis, $F(1,16)=4.71, p<.05$; subject analysis, $F(1,24)=3.79, p<.10]$. We have no ready explana-

Table 1

Results of Experiment 2

\begin{tabular}{lcccccc}
\hline & \multicolumn{7}{c}{ Times (in seconds) } \\
\cline { 2 - 7 } Interpretation & Decision & "Yes" & "No" & Reading & $\begin{array}{c}\% \\
\text { Errors }\end{array}$ & $\begin{array}{c}\text { \% "Yes" } \\
\text { Responses }\end{array}$ \\
\hline \multicolumn{7}{c}{ "Strong Common Ground } \\
Dominant & 3.38 & 3.27 & 4.09 & 3.75 & 7.1 & 86.9 \\
Nondominant & 3.87 & 4.98 & 3.67 & 3.55 & 7.8 & 15.4 \\
Dominant & \multicolumn{7}{c}{ Impoverished Common Ground } \\
Nondominant & 4.31 & 3.78 & 5.33 & 3.65 & 7.5 & 65.9 \\
\hline
\end{tabular}

Note-Decision times represent the mean latencies for the readers' yes/no judgments. 
tion for this difference. There was no interaction between strength of common ground and dominance (both $F \mathrm{~s}<$ 1.0). There were also no reliable differences among the error rates, although they mirror the decision times.

Given the results of Experiment 1, we would expect the readers to give many more "yes" responses to the dominant interpretations than to the nondominant interpretations. This expectation (which is essentially a manipulation check) was confirmed $\left[\min F^{\prime}(1,21)=42.72, p<\right.$ $.001]$. We would, on the other hand, expect the subjects to be more likely to say "yes" to the nondominant interpretation in circumstances in which common ground was impoverished. This interaction between strength and dominance was also confirmed $\left[\min F^{\prime}(1,30)=10.43\right.$, $p<.005]$.

The results of Experiment 2 suggest that readers efficiently employ common ground, as encoded in community membership, in verifying interpretations of ambiguous utterances: Strong common ground leads to swifter confirmation of the preferred readings. What we still do not know, however, is to what degree confirmation based on strong common ground would be equivalent to confirmation based on explicitly stated information. Research on widely shared knowledge structures, such as restaurant scripts, has demonstrated that judgments based on inferences are often indistinguishable from those based on information actually presented (e.g., Bower et al., 1979). In Experiment 3, we looked for comparable equivalence in judgments grounded in community membership.

\section{EXPERIMENT 3}

Common ground can serve as a powerful force to constrain addressees' recovery of speakers' meanings. We noted in the introduction that nongeneric information present in the linguistic environment can endow an utterance with a range of different meanings with little cost to the listener. In Experiment 3, we sought to extend this result to common ground encoded in community membership, but not explicit in the linguistic environment. In doing so, we also hoped to show that judgments based on community membership share properties with those based on more widely shared knowledge.

To fulfill these goals, we added a third version of each of our scenarios, which provided near certain knowledge of the appropriate interpretation of the ambiguity. Consider this example:

You are walking back to your car after a football game between Yale and Brown. While you are waiting to cross a street, a friend complaining about Yale's defeat says, "That game was a disaster."

The scenario specifically mentions that Yale was defeated. Decision times to verify the dominant interpretation (i.e., "Yale lost the game') should be quite brief. Our prediction, even so, is that strong common ground sufficiently constrains verification, such that decision times for the strong-common-ground versions will be equivalent to those for the certain-knowledge versions.

The inclusion of the third version of each scenario made the pool of correctly normed items insufficient to test both the dominant and the nondominant interpretations of each ambiguity in the same experiment. Consequently, we tested dominant interpretations in Experiment $3 \mathrm{~A}$ and nondominant interpretations in Experiment 3B. There were no other differences between the two experiments.

\section{Method}

Subjects. Eighteen Yale undergraduates participated in each experiment. The subjects in Experiment $3 \mathrm{~A}$ were paid for their participation. The subjects in Experiment $3 \mathrm{~B}$ received class credit. All were native speakers of English.

Apparatus and Materials. The apparatus was identical to that used in Experiment 2.

We used 18 of the 20 scenarios from Experiments 1 and 2. Each appeared in three versions: strong common ground, impoverished common ground, and certain knowledge (for examples, see Appendix A). In Experiment $3 \mathrm{~A}$, each scenario concluded with the dominant interpretation of the ambiguity. In Experiment 3B, each scenario concluded with the nondominant interpretation.

Because the proferred interpretations for the experimental items were either all dominant or all nondominant, we added some variation by adjusting half of the filler items to have potentially correct interpretations (an example is given in Appendix B).

Design and Procedure. The three versions of each scenario were distributed across three different lists of items. Each list contained six scenarios of each type of version. Each subject read one list of scenarios in a different random order.

The procedure was identical to that in Experiment 2. The experimental session consisted of 5 practice and 18 experimental scenarios. The subject read each scenario and then made a yes/no decision to indicate agreement with a proffered interpretation of the ambiguous utterance at the end of the scenario.

\section{Results and Discussion}

Table 2 provides performance measures for Experiments $3 \mathrm{~A}$ and $3 \mathrm{~B}$. (Errors, once again, represent observations that fell more than $1 \mathrm{sec}$ beyond the main distribution of responses.) We will describe the results of the two half-experiments (Experiments $3 \mathrm{~A}$ and $3 \mathrm{~B}$ ) separately.

Experiment 3A. Our major prediction for Experiment $3 \mathrm{~A}$ was that decision times would be equivalent for the certain-knowledge and strong-common-ground versions and that those times would differ from the impoverished-common-ground version. The data confirm this prediction: Our initial statistical test was a contrast that compared the mean certain-knowledge and strongcommon-ground times with the impoverished-commonground times $\left[\min F^{\prime}(1,60)=5.68, p<.025\right]$. Tukey tests corroborated the contrast. Impoverished-commonground decision times were reliably slower than certainknowledge times (for both subjects and items, critical difference at $p<.01=0.26 \mathrm{sec}$, both $M S_{\mathrm{e}} \mathrm{s}=0.35$ ), as well as strong-common-ground times (for both subjects and items, critical difference at $p<.05=0.20 \mathrm{sec}$ ). The 
Table 2

Results of Experiments $3 A$ and 3B

\begin{tabular}{|c|c|c|c|c|c|c|}
\hline & \multicolumn{6}{|c|}{ Times (in seconds) } \\
\hline & Decision & "Yes" & "No" & Reading & $\begin{array}{c}\% \\
\text { Errors }\end{array}$ & $\begin{array}{l}\% \text { "Yes" } \\
\text { Responses }\end{array}$ \\
\hline \multicolumn{7}{|c|}{ Experiment 3A (Dominant Interpretation) } \\
\hline $\begin{array}{l}\text { Certain Knowledge } \\
\text { Strong Common Ground } \\
\text { Impoverished Common Ground }\end{array}$ & $\begin{array}{l}2.30 \\
2.34 \\
2.56\end{array}$ & $\begin{array}{l}2.12 \\
2.17 \\
2.27\end{array}$ & $\begin{array}{l}5.90 \\
3.37 \\
3.18\end{array}$ & $\begin{array}{l}2.64 \\
2.82 \\
2.93\end{array}$ & $\begin{array}{l}2.8 \\
1.8 \\
7.4\end{array}$ & $\begin{array}{l}95.2 \\
85.8 \\
68.0\end{array}$ \\
\hline \multicolumn{7}{|c|}{ Experiment 3B (Nondominant Interpretation) } \\
\hline $\begin{array}{l}\text { Certain Knowledge } \\
\text { Strong Common Ground } \\
\text { Impoverished Common Ground }\end{array}$ & $\begin{array}{l}3.02 \\
3.54 \\
3.39 \\
\end{array}$ & $\begin{array}{l}4.11 \\
3.29 \\
3.54 \\
\end{array}$ & $\begin{array}{l}2.94 \\
3.61 \\
3.34 \\
\end{array}$ & $\begin{array}{l}3.07 \\
3.30 \\
3.40\end{array}$ & $\begin{array}{l}2.8 \\
4.6 \\
6.5\end{array}$ & $\begin{array}{r}6.7 \\
21.3 \\
22.8\end{array}$ \\
\hline
\end{tabular}

Note-Decision times represent the mean latencies for the readers' yes/no judgments.

40-msec difference between certain-knowledge and strong-common-ground times was not reliable. These results suggest that the subjects could confirm the dominant interpretation with equivalent ease whether it was grounded in certain knowledge or in community membership.

Again, we can only offer our impressions of the separate "yes" and "no" latencies. We observe that the "yes" responses in circumstances of impoverished common ground are longest and the "no" responses are shortest. This pattern offers limited support for the suggestion that, in these circumstances, readers are entertaining more alternative interpretations for the ambiguity.

For reading times, our expectation based on the results of Experiment 2 was that the subjects would take roughly the same amount of time to understand the ambiguous utterance in the two common-ground versions. However, we expected these reading times to be longer than those for the certain-knowledge versions because the commonground versions required more inferencing, and inferencing often takes time (e.g., Haviland \& Clark, 1974). Again, a contrast supported these expectations $\left[\min F^{\prime}(1,58)=15.94, p<.001\right]$. Tukey comparisons confirmed that certain-knowledge reading times were faster than both strong- and impoverished-commonground times (for item analysis, critical difference at $p<.01=0.17 \mathrm{sec}, M S_{\mathrm{e}}=0.15$; for subject analysis, critical difference at $p<.01=0.14 \mathrm{sec}, M S_{\mathrm{e}}=0.10$ ). Furthermore, there was some evidence that the strongcommon-ground times were faster than the impoverishedcommon-ground times (for item analysis, critical difference at $p<.05=0.13 \mathrm{sec}$; for subject analysis, the critical difference at $p<.05=0.11 \mathrm{sec}$; the difference was $0.11 \mathrm{sec})$. The error data paralleled the results for reading times [item analysis, $F(2,30)=4.19, M S_{\mathrm{e}}=0.14$, $p<.05$; subject analysis, $F(2,30)=3.44, M S_{\mathrm{e}}=0.17$, $p<.05]$.

The analysis of "yes" responses showed an increasing trend from the impoverished- to the strong-commonground to the certain-knowledge versions of each scenario $\left[\min F^{\prime}(2,60)=5.52, p<.01\right]$. Using Tukey compari- sons, we found that each of the three means differed (for item analysis, critical difference at $p<.01=7.9 \%, M S_{\mathrm{e}}$ $=0.033$; for subject analysis, critical difference at $p<$ $.01=7.8 \%, M S_{\mathrm{e}}=0.032$ ). The agreement rates for strong and impoverished common ground very nearly matched those from Experiment 2.

The results of Experiment 3A supported our predictions. We found that, although the subjects took longer to read the ambiguous utterances when they had to infer their meanings, community membership proved to be as potent as certain knowledge as a basis for confirming interpretations. Experiment 3A, however, tested only dominant interpretations. In Experiment 3B, we found a different pattern when we tested nondominant interpretations.

Experiment 3B. Our original prediction was that the decision-time results of Experiment 3B would parallel those of Experiment 3A. However, the data did not support this expectation. Rather than being equivalent in length to the certain-knowledge times, the strongcommon-ground times were longest of all. A post hoc contrast confirmed that the certain-knowledge times were faster than were the grouped strong- and impoverishedcommon-ground times $\left[\min F^{\prime}(1,60)=8.47, p<.01\right]$. Tukey comparisons supported this interpretation. The certain-knowledge decision times were faster than were the impoverished-common-ground times (for item analysis, critical difference at $p<.05=0.30 \mathrm{sec}, M S_{\mathrm{e}}=$ 0.75 ; for subject analysis, critical difference at $p<.05$ $=0.31 \mathrm{sec}, M S_{\mathrm{e}}=0.82$ ) and the strong-common-ground times (for item analysis, critical difference at $p<.01$ $=0.38 \mathrm{sec}$; for subject analysis, $p<.01=0.40 \mathrm{sec}$ ). The impoverished- and strong-common-ground times did not differ. Although we did not predict this pattern of results, it suggests that the interpretations based on common ground are more sensitive to challenges than are those based on certain knowledge. When faced with the nondominant interpretation as a test, the reader must defend his/her assessment of common ground; no protracted defense is necessary with certain knowledge. The situation here is comparable to that in a real conversation when 
later utterances seemingly contradict earlier inferences: Addressees must work to convince themselves that their inferences were correct.

An additional unexpected result was the failure to replicate the strong-common-ground versus impoverishedcommon-ground pattern that we found in Experiment 2 for both the dominant and the nondominant interpretations. This difference could be explained by either or both of two methodological changes: The inclusion of certainknowledge versions of the scenarios and the preponderance of nondominant interpretations. Fortunately, this inversion from Experiment 2 to Experiment 3B does not undermine the more important comparison of certain knowledge versus strong common ground. (The separate "yes" and "no" latencies reinforce our conclusions from the pooled decision-time analysis.)

Unlike decision times, reading times in Experiment 3B fell into the expected pattern. Again, the subjects took longer to read the ambiguous utterances when they were not anchored in certain knowledge $\left[\min F^{\prime}(1,60)=5.38\right.$, $p<.025]$. Tukey comparisons confirmed that certainknowledge reading times were faster than both strongcommon-ground times (for both item and subject analyses, critical difference at $p<.05=0.24 \mathrm{sec}$, both $M S_{\mathrm{e}} \mathrm{s}$ $=0.50$ ) and impoverished-common-ground times (for both item and subject analyses, critical difference at $p<$ $.01=0.31 \mathrm{sec})$. There were no significant differences among error rates in Experiment 3B.

"Yes" responses showed reliable effects $\left[\min F^{\prime}(2,60)\right.$ $=3.10, p<.10$; item analysis, $F(2,30)=5.76, M S_{\mathrm{e}}$ $=0.027, p<.01 ;$ subject analysis, $F(2,30)=6.70, M S_{\mathrm{e}}$ $=0.021, p<.01]$. Tukey comparisons confirmed that the readers said "yes" more often to the certainknowledge versions than to both the strong- and impoverished-common-ground versions (for item analysis, critical value at $p<.01=7.2 \%, M S_{\mathrm{e}}=0.027$; for subject analysis, $p<.01=6.4 \%, M S_{e}=.021$ ). In Experiment 3B, the frequency of "yes" responses did not differ across the two types of common ground. Again, we do not know which change in methodology accounts for this result. Taken together, the results of Experiments $3 \mathrm{~A}$ and $3 \mathrm{~B}$ suggest that assessments of community membership act powerfully to constrain judgments of the interpretations of ambiguous utterances.

\section{GENERAL DISCUSSION}

When engaged in conversation, addressees often must rely on assessments of common ground to determine the meanings of utterances. Imagine, for example, that Andy asks Lisa, "How was your weekend?" and Lisa replies, "It was like being in Conshohocken again." Andy will only completely understand Lisa's utterance if they mutually know what salient event took place in Conshohocken. We would expect Lisa to produce this utterance only if she were certain that she and Andy actually did share appropriate common ground. We would also expect that other people who overhear the utterance-and do not share this knowledge-would be left uncomprehending.

The common ground we have exploited in our experiments was encoded in membership in the Yale undergraduate community. We began our inquiry by creating a broad range of scenarios, each of which ended in an ambiguous utterance. We next selected the subset of scenarios for which a dominant interpretation of the ambiguity was most highly specified by membership in the Yale community. Our question, then, was what role common ground would play in judgments about interpretations of the utterances.

Experiments 1 and 2 demonstrated that the readers made good use of the knowledge they shared with the speakers in the scenarios. Interpretations of the ambiguities were made more confidently and judgments were offered more swiftly when the utterances were embedded in situations with strong common ground. Experiment 3 extended this result to show that interpretations verified against strong common ground were in some respects just as solidly confirmed as those based on certain knowledge. It was only when these interpretations were challenged that their status as inferences was made manifest.

Overall, these experiments demonstrate quite efficient use of information encoded in common ground. As an explanation of impaired performance in circumstances of impoverished common ground, we have suggested that listeners must do something indirect, akin to problem solving: Rather than swiftly applying information that emerges from assessments of community membership, listeners must derive an interpretation of an ambiguity on the basis of other generic knowledge (in our experiments, generic knowledge about average college students and college campuses). What this analysis calls for is an account of the mechanisms of knowledge retrieval that allow for swift and accurate access to constrained partitions of memory. If we imagine all the communities of which we are members (particularly when we extend the notion of community down to the dyad), we begin to appreciate how well tuned retrieval must be. Phenomena of common ground, of the sort we have demonstrated, underscore the sophistication of our memory processes.

\section{REFERENCES}

Aвbott, V., Black, J. B., \& Smith, E. E. (1985). The representation of scripts in memory. Journal of Memory \& Language, 24, 179-199.

Bower, G. B., BLACK, J. B., \& TuRner, T. J. (1979). Scripts in memory for text. Cognitive Psychology, 11, 177-220.

Clark, H. H., \& Carlson, T. B. (1981). Context for comprehension. In J. Long \& A. Baddeley (Eds.), Attention and performance (Vol. 9, pp. 313-330). Hillsdale, NJ: Erlbaum.

Clark, H. H., \& Marshall, C. R. (1981). Definite reference and mutual knowledge. In A. K. Joshi, B. Webber, \& I. Sag (Eds.), Elements of discourse understanding (pp. 10-63). Cambridge: Cambridge University Press.

Clark, H. H., \& Schaefer, E. F. (1987). Concealing one's meaning from overhearers. Journal of Memory \& Language, 26, 209-225.

Clark, H. H., \& Wilkes-Gibas, D. (1986). Referring as a collaborative process. Cognition, 22, 1-39. 
Gerrig, R. J. (1986). Process models and pragmatics. In N. E. Sharkey (Ed.), Advances in cognitive science (pp. 23-42). Chichester, England: Ellis Horwood.

GERRG, R. J. (1989). Empirical constraints on computational theories of metaphor: Comments on Indurkhya. Cognitive Science, 13, 235-241.

Gerrig, R. J., \& Healy, A. F. (1983). Dual processes in metaphor understanding: Comprehension and appreciation. Journal of Experimental Psychology: Leaming, Memory, \& Cognition, 9, 667-675.

GibBs, R. W., JR. (1984). Literal meaning and psychological theory. Cognitive Science, 9, 275-304.

Gibes, R. W., JR. (1986). Comprehension and memory for nonliteral utterances: The problem of sarcastic indirect requests. Acta Psychologia, 62, 41-57.

GibBS, R. W., JR. (1987). Mutual knowledge and the psychology of conversational inference. Journal of Pragmatics, 11, 561-588.

Graesser, A. C., Gordon, S. E., \& SAWyer, J. D. (1979). Recognition memory for typical and atypical actions in scripted activities: Tests of a script pointer + tag hypothesis. Journal of Verbal Learning \& Verbal Behavior, 18, 319-332.

Haviland, S. E., \& Clark, H. H. (1974). What's new? Acquiring new information as a process in comprehension. Journal of Verbal Learning \& Verbal Behavior, 13, 512-521.

IsAACS, E. A., \& CLARK, H. H. (1987). References in conversation between experts and novices. Journal of Experimental Psychology: General, 116, 26-37.

Krauss, R. M. (1987). The role of the listener: Addressee influences on message formulation. Journal of Language \& Social Psychology, 6, 81-98.

Schank, R. C., \& ABELSON, R. P. (1977). Scripts, plans, goals, and understanding. Hillsdale, NJ: Erlbaum.

SCHOBER, M. F., \& ClARK, H. H. (1989). Understanding by addressees and overhearers. Cognitive Psychology, 21, 211-232.

Sharkey, N. E., Mitchell, D. C. (1985). Word recognition in a functional context: The use of scripts in reading. Journal of Memory \& Language, 24, 253-270.

SharkeY, N. E., \& SharkeY, A. J. (1987). What is the point of integration? The loci of knowledge-based facilitation in sentence processing. Journal of Memory \& Language, 26, 255-276.

WALKer, C. H., \& Yekovich, F. R. (1984). Script-based inferences: Effects of text and knowledge variables on recognition memory. Journal of Verbal Learning \& Verbal Behavior, 23, 357-370.

\section{APPENDIX A}

\section{Sample Experimental Stories}

Dominant Interpretation: The book is at Seeley-Mudd. Nondominant Interpretation: The book is at Beinecke.

\section{Strong Common Ground}

You are looking for a book in the Sterling card catalogue. The card is smudged and hard to read. You find your roommate who works in the library on the phone talking to another friend. When your roommate hangs up, you ask, "Is this book in Beinecke Library or is it at Seeley-Mudd Library?"' Your roommate answers, "I hope you're in the mood for a bit of fresh air."

\section{Impoverished Common Ground}

You are looking for a book in the Sterling card catalogue. The card is smudged and hard to read. You find a reference librarian who is on the phone complaining about the weather. After she hangs up, you ask, "Is this book in Beinecke Library or is it at Seeley-Mudd Library?" The librarian answers, "I hope you're in the mood for a bit of fresh air."

Certain Knowledge (Experiments $3 \mathrm{~A}$ and 3B)

You are looking for a book in the Sterling card catalogue. The card is smudged and hard to read. You find your roommate who works in the library on the phone talking to another friend. When your roommate hangs up, you ask, "Is this book in Beinecke Library or is it at Seeley-Mudd Library?" Your roommate sees "Seeley-Mudd" on the card and answers, "I hope you're in the mood for a bit of fresh air."

(Note-Beinecke and Seeley-Mudd are both libraries at Yale.)

Dominant Interpretation: Classical is better music to study with.

Nondominant Interpretation: Rock-and-Roll is better music to study with.

\section{Strong Common Ground}

You are working as a sales clerk in a record store. Your roommate comes in and asks for advice on a new album. You say, "Do you want to get Classical or Rock-and-Roll?" Your roommate replies, "This is to listen to while I study."

\section{Impoverished Common Ground}

You are working as a sales clerk in a record store. A teenager comes in and asks for advice on a new album. You say, "Do you want to get Classical or Rock-and-Roll?"' The teenager replies, "This is to listen to while I study."

\section{Certain Knowledge (Experiments 3A and 3B)}

You are working as a sales clerk in a record store. Your roommate comes in and asks for advice on a new album. You say, "Do you want to get Classical or Rock-and-Roll?" Your roommate walks toward the Classical section and replies, "This is to listen to while I study."

\section{APPENDIX B}

\section{Sample Filler Stories for Experiments 2 and 3}

\section{Interpretation Blatantly False (Experiments 2 and 3)}

At the beginning of the semester, you have to decide what classes to take. You are sitting with your friend and your Blue Book, trying to make up your minds. You are looking for a group four class you can take together. You say, "My favorites are Intro to Biology and Intro to Astronomy. Does either of those sound interesting?" Your friend makes a nasty crack about astronomy and replies, "My father was a biologist."

Interpretation: I prefer Intro to Economics.

\section{No Dominant Interpretation (Experiments $3 \mathrm{~A}$ and 3B)}

It is late and you and your friend are very hungry. The only two places open for miles around are Yorkside Pizza and the Educated Burger. You must decide which place you'd rather eat at. Your friend says, "I' $m$ in the mood for grease tonight." Interpretation: I'm in the mood for Yorkside Pizza.

(Note- The fillers, like the experimental items, were designed for the community of Yale undergraduates. The "Blue Book" is the undergraduate course catalogue. "Group four" is comprised largely of classes in the natural sciences. Both Yorkside Pizza and Educated Burger sell food that could be described as "greasy.")
(Manuscript received July 28, 1989 ; revision accepted for publication November 24, 1989.) 